\title{
Review: assertive community treatment is an effective alternative in severe mental disorders
}

\author{
Marshall M, Lockwood A. Assertive community treatment for people with severe mental disorders. (Cochrane Review, latest version \\ 25 Feb 98). In: the Cochrane Library. Oxford: Update Software.
}

\section{Question}

In patients with severe mental disorders, is assertive community treatment (ACT) an effective alternative to standard community care, hospital based rehabilitation, and case management?

\section{Data sources}

Studies were identified by searching CINAHL, the Cochrane Schizophrenia Group's Register of clinical trials, EMBASE/ Excerpta Medica, Medline, PsycLIT, SCISEARCH, and reference lists of articles.

\section{Study selection}

Studies were selected if they were randomised controlled trials comparing ACT to standard community care, hospital based rehabilitation, or case management in patients between 18 and 65 years of age with severe mental disorders (schizophrenia and schizophrenia-like disorders, bipolar disorder, and depression with psychotic features).

\section{Data extraction}

Data were extracted on number of patients remaining in contact with psychiatric services, extent of psychiatric hospital admissions, clinical and social outcomes, and costs.

\section{Main results}

When ACT was compared with standard community care, patients in the ACT group were more likely to remain in contact with psychiatric services, were less likely to be admitted to hospital, spent less time in hospital, and had better outcomes in terms of accommodation status, employment (table), and patient satisfaction. No differences existed between the groups for mental state, social functioning, or costs (other than reduced cost of hospital care in the ACT group). When ACT was compared with hospital based rehabilitation, patients in the ACT group were less likely to be admitted to hospital and spent less time in hospital, and were more likely to be living alone and to be employed (table). No differences existed between the groups for other clinical and social outcomes, or remaining in contact with services. There were insufficient data to evaluate costs. When ACT was compared with case management, patients in the ACT group spent fewer days in hospital. Insufficient data were available to evaluate all other outcomes.

\section{Conclusion}

ACT is an effective alternative to standard care and to hospital based rehabilitation in patients with severe mental disorders.

ACT v standard care or hospital based rehabilitation in severe mental disorders*

\begin{tabular}{|c|c|c|c|c|}
\hline \multirow[b]{2}{*}{ Outcomes } & \multicolumn{2}{|c|}{ Weighted event rates } & \multirow[b]{2}{*}{$R B I(95 \% C I)$} & \multirow[b]{2}{*}{$N N T(C I)$} \\
\hline & $A C T$ & Standard care & & \\
\hline Contact with services & $82 \%$ & $72 \%$ & $16 \%(10$ to 22$)$ & $11(8$ to 17$)$ \\
\hline \multicolumn{5}{|l|}{ Not admitted to } \\
\hline & $75 \%$ & $60 \%$ & $30 \%(1$ to 67$)$ & 7 (4 to 97$)$ \\
\hline Living independently & $64 \%$ & $50 \%$ & $30 \%(10$ to 53$)$ & $8(5$ to 21$)$ \\
\hline Not homeless & $95 \%$ & $87 \%$ & $11 \%(5$ to 18$)$ & $13(8$ to 32$)$ \\
\hline \multirow[t]{3}{*}{ Employed } & $18 \%$ & $7 \%$ & $198 \%(86$ to 375$)$ & $10(7$ to 18$)$ \\
\hline & \multicolumn{2}{|c|}{ Weighted event rates } & & \\
\hline & $A C T$ & Rehabilitation & $R B I(C I)$ & $N N T(C I)$ \\
\hline $\begin{array}{l}\text { Not admitted to } \\
\text { hospital }\end{array}$ & $67 \%$ & $33 \%$ & $97 \%(48$ to 161$)$ & $3(2$ \\
\hline Living independently & $63 \%$ & $23 \%$ & $163 \%$ (58 to 338$)$ & $3(2$ to 5$)$ \\
\hline Employed & $66 \%$ & $38 \%$ & $76 \%(28$ to 140$)$ & $4(3$ to 8$)$ \\
\hline
\end{tabular}

*Abbreviations defined in glossary; RBI, NNT, and CI calculated from data in article.

$\uparrow$ There was statistically significant heterogeneity among the effect sizes for this outcome.

Source of funding: Manchester University Department of Psychiatry, UK.

For correspondence: Dr M Marshall, Department of Community Psychiatry, University of Manchester, Academic Unit, Royal Preston Hospital, Sharoe Green Lane, Fulwood, Preston, Lancashire PR2 4HT, UK. Fax +44 (0)1772 710772

\section{Commentary}

Critics of deinstitutionalisation argue that there is little evidence of the adequacy of community based care. This implies that people who are mentally ill have been abandoned by mental healthcare delivery systems. However, evidence has been accumulating in support of specific community based interventions. Principal among these is ACT. The review by Marshall and Lockwood presents a detailed, criteria based review of relevant literature, and contributes substantially to our understanding of the specific advantages of this approach.

The strengths of this review include the application of criteria for inclusion of research, the review of instruments to measure continuous data, and thoroughness in ensuring that all studies were included in the preliminary analysis. However, the review does not address the issue of subpopulations. Questions have arisen about the applicability of ACT for mentally ill individuals who are homeless or who suffer from substance use disorders. The authors do not indicate whether sample populations were characterised by these conditions and to what extent outcomes may have been influenced by them.

Important implications arise from this review. Firstly, ACT should be more available. This requires advocacy, a training strategy to prepare practitioners for community based practice, a funding strategy, and a clear definition of the role of healthcare workers. Secondly, the review suggests that heavy users of mental health services be targeted. However, the positive effect on residential stability supports the application of the model to homeless mentally ill subpopulations who may not be in frequent contact with services. Thirdly, to be effective, the model must be implemented properly. Half hearted attempts to provide comprehensive community care do not withstand the scrutiny of outcomes evaluation. Finally, it is important to emphasise the reduction in the extent of admission to hospital when determining resource allocation for ACT. On the basis of the convincing evidence presented by this review, it can be argued that funds should be transferred from hospitals to community based care.

Donald Wasylenki, MD, MSc, FRCPC St Michael's Hospital Toronto, Ontario, Canada 